\title{
A Behavioral Study of Promethazine Interaction with Analgesic Effect of Diclofenac: Pain Combination Therapy
}

\author{
Niloofar Amidi', Zohreh Izadidastenaei², Malihe Araghchian', Davoud Ahmadimoghaddam*
}

${ }^{1}$ Department of Pharmacology and Toxicology, School of Pharmacy, Hamadan University of Medical Sciences, Hamadan, Iran

${ }^{2}$ Neurophysiology Research Center, Hamadan University of Medical Sciences, Hamadan, Iran

\section{Key Words}

antinociceptive, diclofenac, pain, promethazine

\begin{abstract}
Objectives: Pain is considered as a cause of sickness and the most prevalent symptom which makes people visit a physician. Nowadays, combination therapy is becoming useful to relieve chronic and postsurgical pain. The aim of this study was to study the promethazine (as an antihistamine) interactions with antinociceptive effect of diclofenac (as a non-steroidal anti-inflammatory drugs).
\end{abstract}

Methods: In initial part of the study, we investigate the analgesic effect of diclofenac. Using writhing test, we demonstrate that diclofenac significantly reduces writhe response induced by acetic acid in a dose-dependent manner. In this study, we evaluate the combination effect of promethazine on diclofenac analgesic effect.

Results: We observed that diclofenac inhibited pain in the dose dependent manner which means that by increasing dose of diclofenac a significant decrease in pain was observed. This experimental setup allowed calculation of the dose that caused $50 \%$ antinocicep-

Received: May 22, 2019 Reviewed: Jan 22, 2020 Accepted: Feb 3, 2020

(@) This is an Open-Access article distributed under the terms of the Creative Common Attribution Non-Commercial License (http://creativecommons.org/licenses/by-nc/4.0/) which permits unrestricted noncommercial use, distribution, and reproduction in any medium, provided the original work is properly cited. tion (ED50) for diclofenac. The ED50 for diclofenac in this study was determined to be $9.1 \mathrm{mg} / \mathrm{kg}$ according our previous study. Additionally, promethazine was showed a dose-dependent inhibition of writhes. The combination of different doses of promethazine $(2,4$, $6 \mathrm{mg} / \mathrm{kg}$ ) with diclofenac ED50 (9.1 mg / kg) was injected to mice. Promethazine 4 and $6 \mathrm{mg} / \mathrm{kg}$ in combination with diclofenac had significantly led to increase analgesic effect of diclofenac.

Conclusion: In conclusion, these results add important information to the existing knowledge on combination of diclofenac and antihistamine in pain therapies to be used in clinical practice and maybe helpful in designing the future guidelines.

\section{Introduction}

Pain defined by International Association for the Study of Pain as unpleasant sensory and emotional experience associated with actual or potential tissue damage, or described in terms of such damage. Pain is considered as a cause of sickness and the most prevalent symptom which makes people visit a physician. Pharmacotherapy is one of the most important ways of treatment; however, available drugs have limitations in terms of effectiveness and side effects. Nowadays, combination therapy is becoming useful to relieve chronic and postsurgical pain [1-5]. The usage of an adjuvant drug to reduce the dosage and side effects of main drugs is noticeable. Opioid and non-opi- 
oid drugs such as non-steroidal anti-inflammatory drugs (NSAIDs) are used to control pain and inflammation which have significant side effects $[6,7]$.

Diclofenac is a kind of phenyl acetic acid derivate which inhibits cyclooxygenase enzymes. This drug has analgesic, antipyretic and anti-inflammatory effects [8]. Its analgesic effects are related to inhibitory effects of prostaglandin synthesis. Besides main mechanism, there are some secondary mechanisms through which diclofenac does operate [9]. The side effects of diclofenac include gastrointestinal effects, kidney dysfunction and CNS effects such as headache and dizziness [8].

Today, the beneficial effect of combination therapy to relieve chronic and postsurgical pain has been proven. Adjuvant analgesics represent a various group of drugs. These medications were originally developed for a primary indication other than pain, although they may enhance analgesia under specific circumstances when administered simultaneously [10]. The usage of an adjuvant drug to reduce the dosage and side effects of main drug is significant [5].

Antihistamines has been used as an adjuvant analgesic in controlling pain [11]. The effect of antihistamines on pain depends on their dosage, injection sites and evaluation tests [12]. In different studies antagonists of $\mathrm{Hl}$ have shown analgesic effects. Furthermore, a clinical study has shown that diphenhydramine is effective to reduce the cancer pains as an adjuvant to opioid [13]. Additionally, it is suggested that different opioid and non-opioid mechanisms could be active by antihistamines [14]. Promethazine is a Histamine $\mathrm{Hl}$ receptor antagonist that is derived from phenothiazine. It is known as an anti-allergic drug in clinical situations. Additionally, promethazine reacts with different kinds of receptors. It has antimuscarinic activity and leads to sedation, anesthesia, neuroprotective and antiemetic effects. Moreover, promethazine have local analgesic effect similar to those of local anesthetic [12]. Combination therapy of promethazine and sumatriptan showed to be more tolerable and proper for migraine therapy than monotherapy [15].

There might be some secondary mechanism(s), in addition to the main mechanism, through which analgesic drugs exert their analgesic effect. The probable mechanisms can be recognized by experimental studies. Different studies have shown the role of cholinergic, dopaminergic, opioidergic, adrenergic and serotonergic mechanisms in the analgesic effects of drugs [16-19]. The antagonists of these systems are useful to determine the mechanisms of analgesic drugs.

Adjuvant analgesics are used to decrease the dosage of non-steroidal anti-inflammatory drugs and their side effects [20]. It seems that antihistamines in combination with diclofenac can be effective to change the anti-nociceptive effect of diclofenac [21]. For this reason we aimed to study the promethazine interactions with antinociceptive effect of diclofenac.

\section{Material and Methods}

\subsection{Chemicals}

The materials include: Acetic acid (Merck, Germany), Diclofenac (Darou Pakhsh, Iran), Promethazine (Tehran Shimi, Iran), ondansetron (Tehran Shimi, Iran), metoclopramide (Zahravi, Iran), Atropine (Darou Pakhsh, Iran), Naloxene (Darou Pakhsh, Iran).

\subsection{Animals}

Male Naval Medical Research Institute (NMRI) mice (20 - $30 \mathrm{~g}$ ) were purchased from animal house of Hamadan University of Medical Sciences (Hamadan, Iran) and were maintained in 12-/12-h day/night standard conditions with water and pellets ad libitum. The mice were randomly selected. All experiments were approved by the Ethical Committee of the Hamadan University of Medical Sciences (IR.UMSHA.REC.1394.6843) and were carried out in accordance with the Guide for the Care and Use of Laboratory Animals (NIH publication \#85-23, revised in 1985).

\subsection{Writhing test}

The analgesic activity was assessed by the acetic acid abdominal constriction test (writhing test). Acetic acid $(0.7 \%)$ was injected intraperitoneally (i.p.) in a dose volume of $10 \mathrm{ml} / \mathrm{kg}$ body-weight. The injection of main drug or adjuvant was operated 30 minutes before the injection of acetic acid and the injection of inhibitor was operated 30 minutes before the injection of analgesic drug. The total number of writhing was recorded over a period of $10 \mathrm{~min}$, starting $5 \mathrm{~min}$ after acetic acid injection. Each mouse was received one injection and just joined the test in one turn. Antinociceptive activity was expressed as the inhibition percentage of the usual number of writhing in a drug-treated animal compared to the mean number of writhing obtained in control [22]. The percentage of analgesic activity was calculated as following:

$$
\text { Percentage analgesic activity }=\frac{(N c-N t)}{N c} \times 100
$$

where Nc is the average number of stretches in the control group, and Nt is the average number of stretches in the test drug group [23].

\subsection{Study the analgesic effect of Diclofenac}

In this test, animals were divided into five groups $(\mathrm{n}=6)$ [24] as following: the control group (saline $0.9 \%, 10 \mathrm{ml} /$ $\mathrm{kg}$, i.p.); four groups of mice received different doses of diclofenac $(5,10,20,30 \mathrm{mg} / \mathrm{kg})$ [25]. Mice were placed into transparent plastic box and the doses of diclofenac were administrated 30 minutes prior to i.p. injection of acetic acid $0.7 \%$ (in a dose volume of $10 \mathrm{ml} / \mathrm{kg}$ body-weight) for ability to suppress abdominal constriction responses. Afterward, their responses counted throughout continuous observation for $10 \mathrm{~min}$. It has to be mentioned that each animal was used only once. 


\subsection{Study the analgesic effect of Promethazine}

Herein, animals were divided into four groups $(\mathrm{n}=6)$ as following: the control group (saline $0.9 \%, 10 \mathrm{ml} / \mathrm{kg}$, i.p.); three groups of mice received different doses of promethazine $(2,4,6 \mathrm{mg} / \mathrm{kg})$ [26]. Mice were placed into transparent plastic box and the doses of promethazine were administrated 30 minutes prior to i.p. injection of acetic acid $0.7 \%$ (in a dose volume of $10 \mathrm{ml} / \mathrm{kg}$ body-weight) for ability to suppress abdominal constriction responses. Afterward, their responses counted throughout continuous observation for $10 \mathrm{~min}$. It has to be mentioned that each animal was used only once.

\subsection{Study the analgesic effect of Diclofenac and Promethazine combination}

In this experimental setup, animals were divided into four groups $(n=6)$ as following: the control group (diclofenac effective dose for $50 \%$ of the population (ED50), $9.1 \mathrm{mg} / \mathrm{kg}$, i.p.); three groups of mice received diclofenac $(9.1 \mathrm{mg} / \mathrm{kg})$ and different doses of promethazine $(2,4$, $6 \mathrm{mg} / \mathrm{kg}$ ). Mice were placed into transparent plastic box and the effective dose (ED50) of diclofenac $(9.1 \mathrm{mg} / \mathrm{kg}$ ) and different doses of promethazine $(2,4,6 \mathrm{mg} / \mathrm{kg})$ were administrated 30 minutes prior to i.p. injection of acetic acid $0.7 \%$ (in a dose volume of $10 \mathrm{ml} / \mathrm{kg}$ body-weight) for ability to suppress abdominal constriction responses. Then, their responses counted during continuous observation for $10 \mathrm{~min}$. It has to be mentioned that each animal was used only once.

\subsection{Study the possible mechanism of Diclofenac analgesic activity through different pathways}

The possible contribution of opioid, serotonin, dopamine, and cholinergic receptor in antinociceptive effect of diclofenac was assessed by antagonist studies. Four groups $(n=6)$ of mice were received diclofenac in combination with inhibitors of different pain pathways (naloxone, ondansetron, atropine and metoclopramide). In this part, the antagonists of different pain pathways were injected 30 minutes prior administration of diclofenac 30 $\mathrm{mg} / \mathrm{kg}$ and subsequntly 30 minutes later the acetic acid $(0.7 \%)$ was injected to mice. Afterward, their responses counted throughout continuous observation for $10 \mathrm{~min}$. It has to be mentioned that each animal was used only once.

\subsection{Statistical analysis}

In this study statistical analysis operates by software Spss20. For each group of experiments, the number of animals was $n \geq 6$. Data are presented as mean \pm SD. Statistical significance was examined by one-way ANOVA followed by Turkey's test. The figures were draw using Graphpad Prism 6 software (Graphpad Software, Inc., San Diego, CA). A difference of $\mathrm{p}<0.05$ was considered significant.

\section{Results}

\subsection{Analgesic effect of Diclofenc}

In this test, application doses of 5, 10, 20 and $30 \mathrm{mg} / \mathrm{kg}$ (p $<0.001$ ) were effective in decreasing writhing compared to the control group (Fig. 1). Diclofenac at dose of $5 \mathrm{mg} / \mathrm{kg}$ had inhibited pain $42.9 \%$ compared to control group which was a significant difference. Diclofenac $10 \mathrm{mg} / \mathrm{kg}$ had inhibited pain $46.6 \%$, diclofenac $20 \mathrm{mg} / \mathrm{kg}$ had inhibited pain $61.6 \%$, and diclofenac $30 \mathrm{mg} / \mathrm{kg}$ had inhibited pain $71.5 \%$. Additionally, injection of the $30 \mathrm{mg} / \mathrm{kg}$ dose of the diclofenac were significantly effective in decreasing writhing compared to the group which were recievd diclofenac 5 and $10 \mathrm{mg} / \mathrm{kg}(\mathrm{P}<0.001)$. We observed that diclofenac inhibited pain in the dose dependent manner which means that by increasing dose of diclofenac a significant decrease in pain was observed (Fig. 1). This experimental setup allowed calculation of the dose that caused $50 \%$ antinociception (ED50) for diclofenac. The ED50 for diclofenac in this study was determined to be $9.1 \mathrm{mg} / \mathrm{kg}$ according our previous study [22].

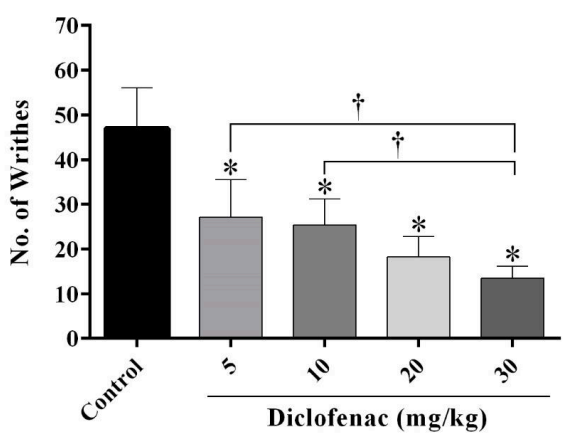

Figure 1 The dose-related effect of diclofenac in the writhing test. Each column represents the writhing response of 6 animals per group $(\mathrm{N}=6)$ as mean $\pm \mathrm{SD}$. ${ }^{*} \mathrm{p}<0.05$ as significant difference to respect control treated with vehicle. $\dagger p<0.05$ as significant difference to diclofenac $30 \mathrm{mg} / \mathrm{kg}$.

\subsection{Analgesic effect of Promethazine}

To investigate the possible antinociceptive effect of promethazine, different doses of promethazine was used. In this laboratory model, application doses of 2, 4, $6 \mathrm{mg} / \mathrm{kg}$ $(p<0.001)$ were effective in decrease of writhing response compared to the control group (Fig. 2). It was observed that promethazine $2,4,6 \mathrm{mg} / \mathrm{kg}$ had inhibited writhes by $43.2 \%, 53.9 \%$ and $62.3 \%$ which were significantly different from control group (Fig. 2).

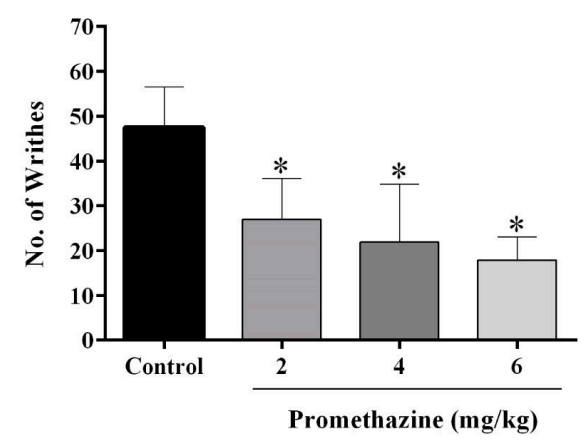


Figure 2 The dose-related effect of promethazine in the writhing test. Each column represents the writhing response of 6 animals per group $(\mathrm{N}=6)$ as mean $\pm \mathrm{SD} .{ }^{*} \mathrm{p}<0.05$ as significant difference to respect control treated with vehicle.

\subsection{Analgesic effect of Diclofenac in combina- tion with Promethazine}

In order to consider the interaction of diclofenac with promethazine, diclofenac ED50 and promethazine 2, 4, 6 mg / kg were used (Fig. 3). The results have shown that promethazine $2 \mathrm{mg} / \mathrm{kg}$ in combination with diclofenac had inhibited pain $59 \%$ which was not significantly different with diclofenac group. The combination of diclofenac and promethazine $4 \mathrm{mg}$ / $\mathrm{kg}$ had inhibited writhes $71.6 \%$ which was significantly different from diclofenac ED50 group $(\mathrm{P}<0.001)$. Using diclofenac ED50 along with promethazine $6 \mathrm{mg} / \mathrm{kg}$ have resulted in pain inhibition by $90.2 \%$, which was significantly different from diclofenac ED50 $(\mathrm{P}<0.001)$. Additionally, the result of this experiment showed that combination of diclofenac and promethazine $(2,4 \mathrm{mg} / \mathrm{kg})$ was significantly decreasing writhing compared to the combination of diclofenac and promethazine $6 \mathrm{mg} / \mathrm{kg}(\mathrm{P}<0.001$ and $\mathrm{P}<0.01$, respectively $)$. The result of this experiment was shown that promethazine could increase analgesic effect of diclofenac (Fig. 3).

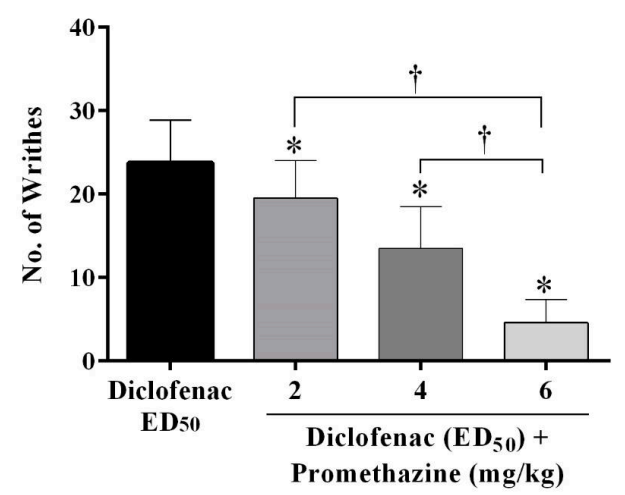

Figure 3 The combination effect of diclofenac ED50 and promethazine on the anti-nociceptive effect of the diclofenac in the writhing test. Each column represents the writhing response of 6 animals $(n=6)$ per group as mean \pm SD. ${ }^{*} \mathrm{p}<0.05$ as significant difference to respect control treated with ED50. $+\mathrm{p}<0.05$ as significant difference to promethazine $6 \mathrm{mg} / \mathrm{kg}$ group.

\subsection{The effect of inhibitors of different analgesic pathways on analgesic effect of Diclofenac}

In this experimental setup, it was revealed that using naloxone (1 mg / kg; an opoidic receptor antagonist) [27] or ondansetron ( $0.5 \mathrm{mg} / \mathrm{kg}$; serotonin receptor antagonist) [28] or atropine ( $1 \mathrm{mg} / \mathrm{kg}$; cholinergic receptor) [27] plus diclofenac $30 \mathrm{mg} / \mathrm{kg}$ caused the reverse of the pain relief effects of the diclofenac $(\mathrm{P}<0.05)$. The results have shown that inhibition of writhes by naloxone, ondansetron and atropine were $50.7 \%, 57.1 \%$ and $43.2 \%$, respectively. However, the combination of metoclopramide ( $1 \mathrm{mg} / \mathrm{kg}$; dopamine receptor antagonist) [29] plus diclofenac $30 \mathrm{mg} /$ $\mathrm{kg}$ inhibited writhes $69.2 \%$ which was not significantly effective in reversing of the pain relief effect of diclofenac $30 \mathrm{mg} / \mathrm{kg}$. Additionally, the combination of atropine or naloxone plus diclofenac were significantly different from combination of metoclopramide and diclofenac in terms of writhes inhibition $(\mathrm{P}<0.05)$.

\section{Discussion}

In this study, we describe the impact of promethazine as an adjuvant on analgesic effect of diclofenac. Additionally, we show the possible mechanism of action which might diclofenac exert its analgesic effect. Available knowledge on combination therapy of pain shows that the combination of antihistamine and NSAIDs or opioids are commonly used in clinical practice with generally good results $[13,16]$. We hypothesized that a similar scenario might occur when promethazine and diclofenac are combined and, therefore, we investigated the combination effect as well as the possible mechanism of action involved in the analgesic effect of diclofenac.

In initial part of the study, we investigate the analgesic effect of diclofenac. Using writhing test, we demonstrate that diclofenac significantly reduces writhe response induced by acetic acid (Fig. 1) which is in consistence with the results of other study [21].

According to our previous study, by drawing dose-response figure and linear regression analysis, $\mathrm{ED}_{50}$ was determined $9.1 \mathrm{mg} / \mathrm{kg}$ [22]. However, in other studies ED50 was determined to be 8.1 [21] and $9.8 \mathrm{mg} / \mathrm{kg}$ [26]. It seems that these differences are because of dissimilarities between concentrations of acetic acid and the time of writhes counting.

The role of histaminergic system in controlling pain has been represented in different studies $[13,30]$. It has been postulated that histamine plays role in controlling pain by $\mathrm{H} 2$ receptor [31]. For this reason, to investigate the role of promethazine as an adjuvant analgesic, a range of promethazine doses from 2 to $6 \mathrm{mg} / \mathrm{kg}$ was tested (Fig. 2). Promethazine has showed a dose-dependent inhibition of writhes, which is in consistence with our results [32].

Diphenhydramine has been studied as an analgesic adjuvant [13]. It has been shown that diphenhydramine was effective on relieving resistant pains of cancer when it was added to different analgesic regimen as an adjuvant. In patients who had cancer and they were resistant to oral, injection and epidural use of opioids, diphenhydramine had reduced the pain by being used continuously [13]. Additionally, different studies have proved that analgesic effect of diclofenac can be increased by some adjuvant [21, 33]. In this study, we evaluate the combination effect of promethazine on diclofenac analgesic effect. The combination of different doses of promethazine with diclofenac was injected to mice. In this experimental setup, we used diclofenac $\mathrm{ED}_{50}(9.1 \mathrm{mg} / \mathrm{kg})$, we observed a significant decrease in writhes number which consequently lead to increase analgesic effect of diclofenac (Fig. 3). Promethazine 4 and $6 \mathrm{mg} / \mathrm{kg}$ in combination with diclofenac had 
significantly led to increase analgesic effect of diclofenac (Fig. 3). Accordingly, the results suggest the efficacy of this combination which might lead to decrease the dose of diclofenac and consequently decrease its side effect. This finding might be helpful to create future guidelines for relieve of pains using diclofenac. The study of Paz-Compos et al. suggested that diclofenac-curcumin combination may have therapeutic advantages for the clinical treatment of inflammatory pain [33]. The synergism effect of diclofenac in combination with clonidine or diclofenac with phenylephrine have been demonstrated in other study as well [21].

In order to study probable mechanisms of diclofenac, other than inhibiting cyclooxygenase, the role of opioidergic, serotonergic, cholinergic and dopaminergic systems were studied. Naloxone is competitive antagonist of opioidergic receptors which can antagonize analgesic and other effects of morphine by $\mu, \sigma^{\prime}$ and $K$ receptors [24]. Naloxone has proved dose dependent effects on controlling the pain of human and animals [34]. In experimental studies, very low doses of naloxone have shown analgesic effects [35]. The results of this study suggest that naloxone can lead to increase the number of writhes which were inhibited using diclofenac Fig. 4. This outcome indicates that opioidergic system may play role in analgesic effect of diclofenac. This finding is in consistence with other study which has showed that i.p. injection of naloxone has reversed the analgesic effect of diclofenac [36]. Pernia Andrade et al. have shown that naloxone $1 \mathrm{mg} / \mathrm{kg}$ has inhibited analgesic effect of Lysine acetylsalicylate (injection form of Aspirin) in hot plate and tail flick tests [37]. Additionally, it has been reported that naloxone can antagonize analgesic effect of some non-opioidergic drugs such as acetaminophen and can act as an antagonist of gabanergic receptors [38]. There are some reports which have been shown that 5-hydroxytryptamine 3 receptors (5HT3) play role in inducing and inhibiting pain [39, 40]. These effects depend on the location of analgesic receptors, the way of administration and evaluating pain test [40]. In order to study the possible role of serotonin on analgesic effect of diclofenac, the ondansetrone as an antagonist of 5HT3 receptors was used. We observed significant increase in the number of writhes (Fig. 4) which means that ondansetrone inhibited analgesic effect of diclofenac. This result indicates that serotonin receptors, especially $5 \mathrm{HT} 3 \mathrm{might}$ play role in analgesic effect of diclofenac. In accordance with our study, other investigation has shown that ondansetrone had decreased analgesic effect of diphenyl diselenide [29]. Different studies have been shown the effect of 5HT1A, 5HT2A and $5 \mathrm{HT} 3$ receptors in the analgesic effect of aspirin and acetaminophen [41, 42].

Atropine, an antagonist of the muscarinic acetylcholine receptors, was use to investigate the effect of muscarinic receptors in analgesic activity of diclofenac [43]. In this study, atropine $1 \mathrm{mg} / \mathrm{kg}$ has significantly inhibited analgesic effect of diclofenac (Fig. 4). This result suggests the possible analgesic effect of diclofenac throughout cholinergic pathway. Intraperitoneally injection of atropine has significantly antagonized effect of NSAIDs in tail flick test [43]. Dopamine $\mathrm{D}_{1}$ and $\mathrm{D}_{2}$ receptor antagonists have been reported to play role in analgesic effect [27, 44]. In this study, metoclopramide, as a dopaminergic antagonist, increase the number of writhes (Fig. 4); however, this increase was not statistically significant. This finding indicates the possible involvement of dopamine receptor in the analgesic effect of diclofenac. Different studies have shown that $\mathrm{D}_{2}$ agonists and indirect stimulant of dopamine receptors have shown analgesic effect in different models of pain in animals $[25,27,44]$.

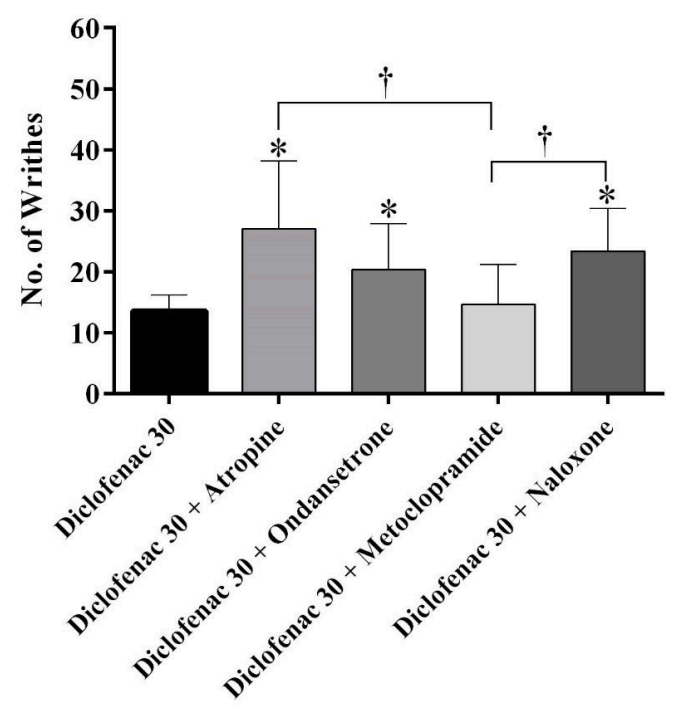

Figure 4 The influence of the pre-treatment with naloxone (1 mg / kg), ondansetron ( $0.5 \mathrm{mg} / \mathrm{kg}$ ), atropine ( $1 \mathrm{mg} / \mathrm{kg}$ ) and metoclopramide $(1 \mathrm{mg} / \mathrm{kg})$ on the anti-nociceptive effect of the diclofenac $(30 \mathrm{mg} / \mathrm{kg})$ in the writhing test. Each column represents the writhing response of 6 animals per group as mean \pm SD. ${ }^{*} \mathrm{p}<$ 0.05 as significant difference compare to Diclofenac $30 \mathrm{mg} / \mathrm{kg}$; $†$ $\mathrm{p}<0.05$ as significant difference compare to the combination of Diclofenac $30 \mathrm{mg} / \mathrm{kg}$ and metoclopramide.

\section{Conclusion}

This study demonstrates the combination effect of promethazine on diclofenac analgesic effect. Promethazine showed to be effective in increasing analgesic effect of diclofenac, which may suggest usage of lower diclofenac dose with consequently lower side effects. According to the results, we suggest that at least some parts of analgesic effect of diclofenac might be due to interaction with opioidergic, serotonergic, cholinergic and dopaminergic pathways. However, more studies should be performed to evaluate the precise pharmacokinetic and pharmacodynamics profile of such combination. In conclusion, these results add important information to the existing knowledge on combination of diclofenac and antihistamine in pain therapies to be used in clinical practice and maybe helpful in designing the future guidelines.

\section{Acknowledgment}

This work was partially supported by vice-chancellor for research and technology, Hamadan University of Medical 
Sciences, Hamadan, Iran (Grant No. 940215634). We would like to thank Masoomeh Taheri for technical assistance.

\section{Conflict of interest}

The authors declare that they have no conflict of interest.

\section{References}

1. Bennett RM, et al. Tramadol and acetaminophen combination tablets in the treatment of fibromyalgia pain: a double-blind, randomized, placebo-controlled study. The American journal of medicine. 2003;114(7):537-45.

2. Backonja MM, G. Irving, C Argoff. Rational multidrug therapy in the treatment of neuropathic pain. Current pain and headache reports. 2006;10(1):34-8.

3. Kerrick JM, et al. Low-dose amitriptyline as an adjunct to opioids for postoperative orthopedic pain: a placebo-controlled trial. Pain. 1993;52(3):325-30.

4. Gilron I, et al. Morphine, gabapentin, or their combination for neuropathic pain. New England Journal of Medicine. 2005;352(13):1324-34.

5. Mao J, MS Gold. Combination drug therapy for chronic pain: a call for more clinical studies. The Journal of Pain. 2011;12(2):157-66.

6. Nili-Ahmadabadi A, et al. The occurrence of acetaminophen/codeine as an adulterant in herbal analgesic supplements in Hamadan, Iran: A pilot study. Complementary therapies in medicine, 2019;42:223-5.

7. Aghababaei R, et al. Occurrence of bacterial and toxic metals contamination in illegal opioid-like drugs in Iran: a significant health challenge in drug abusers. DARU Journal of Pharmaceutical Sciences. 2018;26(1):77.

8. Gan T.J., Diclofenac: an update on its mechanism of action and safety profile. Current medical research and opinion. 2010;26(7):1715-31.

9. Vellani, V., et al. Effects of NSAIDs and paracetamol (acetaminophen) on protein kinase C epsilon translocation and on substance $\mathrm{P}$ synthesis and release in cultured sensory neurons. Journal of pain research. 2013;6:111.

10. Knotkova H, M Pappagallo. Adjuvant analgesics. Anesthesiology clinics. 2007;25(4):775-86.

11. Rumore MM, DA Schlichting. Clinical efficacy of antihistaminics as analgesics. Pain, 1986. 25(1): p. 7-22.

12. Ashmawi HA, et al. Analgesic effects of $\mathrm{H} 1$ receptor antagonists in the rat model of formalin-induced pain. Brazilian Journal of Anesthesiology. 2009;59(4):461-70.

13. Santiago-Palma J, et al. Diphenhydramine as an analgesic adjuvant in refractory cancer pain. Journal of pain and symptom management. 2001;22(2):699-703.

14. Stevens CW, DN MacIver, LC Newman. Testing and comparison of non-opioid analgesics in amphibians. Journal of the American Association for Laboratory Animal Science. 2001;40(4):23-7.

15. Asadollahi S, et al. Promethazine plus sumatriptan in the treatment of migraine: a randomized clinical trial. Headache: The Journal of Head and Face Pain, 2014;54(1):94-108.

16. Raffa R. Antihistamines as analgesics. Journal of clini- cal pharmacy and therapeutics. 2001;26(2): 81-5.

17. Jääskeläinen SK, et al. Role of the dopaminergic system in chronic pain-a fluorodopa-PET study. Pain, 2001;90(3):257-60.

18. Schrepf A, et al. Endogenous opioidergic dysregulation of pain in fibromyalgia: a PET and fMRI study. Pain. 2016;157(10):2217.

19. Sommer C. Serotonin in pain and analgesia. Molecular neurobiology. 2004;30(2):117-25.

20. Picazo A, G Castañeda-Hernández, MI Ortiz. Examination of the interaction between peripheral diclofenac and gabapentin on the $5 \%$ formalin test in rats. Life sciences. 2006;79(24):2283-7.

21. Miranda HF, F Sierralta, G Pinardi. An isobolographic analysis of the adrenergic modulation of diclofenac antinociception. Anesthesia \& Analgesia. 2001;93(2):430-5.

22. Zeraati F, M Araghchian, MH Farjoo. Ascorbic Acid interaction with analgesic effect of morphine and tramadol in mice. Anesthesiology and pain medicine. 2014;4(3).

23. Zhang L, et al. Anti-inflammatory and analgesic effects of ethanol and aqueous extracts of Pterocephalus hookeri (CB Clarke) Höeck. Journal of ethnopharmacology. 2009;123(3):510-4.

24. Gannon WL, RS Sikes. Guidelines of the American Society of Mammalogists for the use of wild mammals in research. Journal of Mammalogy. 2007;88(3):809-23.

25. Ayoub SS, et al. The involvement of a cyclooxygenase 1 gene-derived protein in the antinociceptive action of paracetamol in mice. Eur J Pharmacol. 2006;538(13):57-65.

26. Farshchi A, et al. Antinociceptive effect of promethazine in mice. Iranian Journal of Basic Medical Sciences. 2009;12(3):140-5.

27. Pinheiro MM, et al. Antinociceptive activity of fractions from Couroupita guianensis Aubl. leaves. Journal of ethnopharmacology. 2010;127(2):407-13.

28. Santos AR, et al. Mechanisms involved in the antinociception caused by agmatine in mice. Neuropharmacology. 2005;48(7):1021-34.

29. Zasso FB, et al. On the mechanisms involved in antinociception induced by diphenyl diselenide. Environmental toxicology and pharmacology. 2005;19(2):283-9.

30. Mobarakeh JI, et al. Enhanced antinociceptive effects of morphine in histamine $\mathrm{H} 2$ receptor gene knockout mice. Neuropharmacology. 2006;51(3):612-22.

31. Tamaddonfard E, et al. Central effect of histamine in a rat model of acute trigeminal pain. Pharmacological Reports. 2008;60(2):219.

32. Galeotti N, C Ghelardini, A Bartolini. The role of potassium channels in antihistamine analgesia. Neuropharmacology. 1999;38(12):1893-1901.

33. De Paz-Campos MA, et al. Synergistic effect of the interaction between curcumin and diclofenac on the formalin test in rats. Phytomedicine. 2014;21(12):1543-8.

34. Rios L, JJ Jacob. Local inhibition of inflammatory pain by naloxone and its N-methyl quarternary analogue. European journal of pharmacology. 1983;96(3-4):277-83.

35. Tsuruoka M, et al. Effects of yohimbine on naloxone-induced antinociception in a rat model of inflammatory hyperalgesia. European journal of pharmacology. 
1998;348(2):161-5.

36. Björkman R. Central antinociceptive effects of non-steroidal anti-inflammatory drugs and paracetarmol. Acta Anaesthesiologica Scandinavica. 1995;39(s103):7-44.

37. Pernia-Andrade AJ, V Tortorici, $H$ Vanegas. Induction of opioid tolerance by lysine-acetylsalicylate in rats. Pain. 2004;111(1):191-200.

38. Madenoğlu $\mathrm{H}$, et al. Effects of naloxone and flumazenil on antinociceptive action of acetaminophen in rats. Current Therapeutic Research. 2010;71(2):111-7.

39. Dharmshaktu P, V Tayal, BS Kalra. Efficacy of antidepressants as analgesics: a review. The Journal of Clinical Pharmacology. 2012;52(1):6-17.

40. Zeitz KP, et al. The 5-HT3 subtype of serotonin receptor contributes to nociceptive processing via a novel subset of myelinated and unmyelinated nociceptors. The Journal of neuroscience. 2002. 22(3):1010-9.

41. Mallet C, et al. Endocannabinoid and serotonergic systems are needed for acetaminophen-induced analgesia. Pain, 2008. 139(1):190-200.

42. Groppetti A, et al. Effect of aspirin on serotonin and met-enkephalin in brain: correlation with the antinociceptive activity of the drug. Neuropharmacology. 1988;27(5):499-505.

43. Pinardi G, F Sierralta, H Miranda. Atropine reverses the antinociception of nonsteroidal anti-inflammatory drugs in the tail-flick test of mice. Pharmacology Biochemistry and Behavior. 2003;74(3):603-8.

44. Katyal J, YK Gupta. Dopamine release is involved in antinociceptive effect of theophylline. International Journal of Neuroscience. 2012;122(1):17-21. 